\title{
Is laparoscopic appendicectomy safe in the hands of junior trainees in surgery?
}

\author{
N. Harivallavan ${ }^{1}$, M. D. Jayawardene ${ }^{1}$, S. A. Piyarathne ${ }^{2}$, A Arulprashath ${ }^{1}$, S. D. Iddamalgoda ${ }^{1}$, S. Anton \\ Swarnan $^{1}$, A. A. Pathirana ${ }^{2}$ \\ 'Colombo South Teaching Hospital, Sri Lanka \\ ${ }^{2}$ Faculty of medical Sciences, University of Sri Jeyewardenapura, Sri Lanka
}

Keywords: laparoscopic appendicectomy; trainees; safety

\begin{abstract}
\section{Introduction}

Laparoscopic appendicectomy (LA) is considered as the mainstay of treatment in acute appendicitis. LA is a basic laparoscopic procedure and therefore can be used as a training tool for surgical trainees. It is considered an index operation for junior surgical trainees. This study aims to assess whether LA is safe to be carried out by a junior surgical trainee.
\end{abstract}

\section{Methodology}

The study was conducted at a tertiary care unit in Colombo. Data were collected retrospectively. A total of 152 LA (including those which were converted to open appendicectomy) performed between January 2018 to May 2019 , by surgical trainees (both junior and senior) were included. Gender, age, initial investigation findings, intraoperative findings, operative time, hospital stay, postoperative complications and histology data were analysed. Findings were compared in two groups - operated by junior and senior surgical trainees.

\section{Results}

One hundred and three surgeries were performed by junior trainees while 49 were performed by senior trainees. There was no significant difference in complicated appendicitis ( $21.4 \%$ vs $34.7 \%$ ), operative time ( $71 \mathrm{~m}$ vs $68 \mathrm{~m}$ ), conversion rate $(12.6 \%$ vs $16.3 \%)$ and hospital stay ( $3 \mathrm{~d}$ vs $3 \mathrm{~d})$ between these two groups. The overall complication rate was $3.9 \%$.

\section{Conclusion}

Our findings were comparable to previously published data and no statistically significant difference was noted between the two trainee groups in terms of operative finding, hospital stay and postoperative complications. The results suggest that LA can safely be performed by the junior surgical trainees with acceptable outcomes.

\footnotetext{
Correspondence: N. Harivallavan

E-mail: nagenthiramhari@gmail.com

iD https://orcid.org/0000-0001-6758-6323

Received: 27-04-2020 Accepted: 26-08-2020

DOI: http://doi.org/10.4038/sljs.v38i2.8686
}

\section{Introduction}

The overall lifetime risk of developing acute appendicitis is $8.6 \%$ for males and $6.7 \%$ for females; the lifetime risk of appendicectomy is around $12 \%$ in males and $23 \%$ in females [1]. Despite emerging data on the possibility of managing many patients with acute uncomplicated appendicitis conservatively, appendicectomy is still considered as the mainstay of treatment in most settings in both complicated and uncomplicated cases [2]. There are open and laparoscopic techniques for appendicectomy. With the increasing popularity of minimal access surgeries, laparoscopic appendicectomy (LA) is fast becoming the mainstay of treatment. Appendicectomy is considered an index operation for junior surgical trainees [3]. In the modern era, all surgical trainees are expected to have laparoscopic skills. LA is a basic laparoscopic procedure and therefore can be used as a training tool. But any surgical procedure in the training programme should be monitored for safety.

This study aims to assess whether LA is safe to be carried out by a junior surgical trainee (JT, a first-year trainee in surgery) without much prior experience in minimally invasive surgery.

\section{Methodology}

This study was conducted at a tertiary care centre in Sri Lanka. A total of 152 cases of laparoscopic appendicectomy (including those which were converted to open appendicectomy) performed between January 2018 and May 2019, by surgical trainees (both junior and senior), were included. A junior trainee (JT) was defined as a surgical registrar in the first year of his/her surgical training. A senior trainee (ST) was defined as a surgical senior registrar (postMD trainee). Those who had previous surgical experience on laparoscopic surgeries were excluded from the junior trainee group even if he/she were in their first-year pre-MD surgical training (i.e. a previous Senior House Officer in a surgical unit who had performed laparoscopic work).

All junior trainees had undergone initial training in basic laparoscopic skills before starting the MD surgery training program by taking part in a mandatory workshop on Basic Laparoscopic Skills conducted by the College of Surgeons of Sri Lanka. They had assisted for several LA in the initial period of training and subsequently performed the procedure 
under the supervision of a consultant. Once confident, junior trainees could perform LA independently, with a senior trainee (ST) present in the theatre.

The basic demographic data (gender, age), initial investigation findings (white cell count, CRP), intraoperative findings (degree of inflammation, amount of blood loss, operative time), hospital stay, postoperative complications and histology of patients who underwent LA during the study period were retrospectively gathered and recorded separately for JT and ST groups. Ethical clearance was obtained from the ethics review committee of the institution. SPSS version 25 was used for data analysis. The Independent t-test was used for quantitative variables and the chi-square test was used for qualitative variables. A p-value of less than 0.05 was considered statistically significant.

\section{Results}

One hundred and three LA were performed by JT while 49 were performed by ST. There was no statistically significant difference between these two groups in terms of age, gender, pre-operative inflammatory markers, and time duration from onset of symptoms to operation. (Table 1)

There was no significant difference in operative time $(71 \mathrm{~m}$ vs $68 \mathrm{~m}, \mathrm{p}=0.58)$, conversion rate $(12.6 \% \mathrm{vs} 16.3 \%, \mathrm{p}=0.53)$ and hospital stay ( $3 \mathrm{~d}$ vs $3 \mathrm{~d}, \mathrm{p}=0.13$ ) between these two groups (Table 2). The incidence of abscess formation and perforation of the appendix (complicated appendicitis) was $21.4 \%$ and $34.7 \%$ in junior and senior trainees' groups respectively, with a p-value of 0.079 .

Two incidents of surgical site infection and one case of residual abscess were observed in the JT group. Observed complications in the ST group were one surgical site infection and one paralytic ileus. An inflamed appendix was confirmed histologically in 150 cases, while two appendices were not inflamed. These non-inflamed appendices were in the JT group.

For an unbiased comparison of JT and ST performances, we analysed after the exclusion of appendicectomy done for patients with complicated appendicitis. Subsequent findings showed that there was no statistically significant difference in terms of age, gender, pre-operative inflammatory markers, and time duration from onset of symptoms to operation between these two groups (Table 3). Even after the exclusion of surgeries for complicated appendicitis, the cohort with surgeries for uncomplicated appendicitis did not show any statistically significant difference in operative time, conversion rate, days of hospital stay, or postoperative complications (Table 4).

\section{Discussion}

Surgical training programmes have indicated index operations which are mandatory to be performed by trainees according to the level of their training. With the development of minimally invasive surgery, the necessary skills to perform these procedures are vital and it is necessary to select operations that are suitable for training the JT. Appendicectomy is a commonly performed procedure in most general surgical units, and performing this with minimally invasive methods is accepted as a safe procedure.

To obtain knowledge, skills, and values of the surgical profession, the workplace remains the principal site. It is believed that the theoretical concept of communities of practice can aptly be applied for surgical training [4].

Lave and Wenger defined the concept of communities of practice in which legitimate peripheral participation is a central notion [5]. A newcomer initially doing tasks peripheral to a community should get meaningful opportunities to interact and learn from the old-timers to be gradually allowed to undertake tasks central to the community [6]. It is the JT that plays this role initially in the setting of a surgical community. JT being a peripheral participant in the surgical community at first, gaining opportunities to perform meaningful surgical tasks in proportion to his/her ability, progressively improves upon developing the knowledge, skills, and confidence in surgical procedures. With time, the JT will move toward the centre of the community where he/she will be allowed to perform the entire surgical procedure. This theoretical basis of workplace learning applies to our study.

JT who has taken part in a basic laparoscopic skills workshop can be allowed to perform components of a minimally invasive procedure under direct supervision. Once confident, a procedure such as laparoscopic appendicectomy can be allowed to be performed by the JT. This helps the JT to gain the necessary skills and more importantly confidence in laparoscopic work, without compromising patient safety.

Our study showed that the outcome of LA done by JT was comparable to those done by ST, strengthening the notion that LA qualifies as a laparoscopic surgery a JT can be offered to perform on their own under senior supervision.

The prevalence of complicated appendicitis was $21.4 \%$ and $34.7 \%$ in this study in JT and ST groups respectively. The overall prevalence of complicated appendicitis was $25.6 \%$ $(39 / 152)$ which is higher than what had been reported in published studies. Yilmaz $\mathrm{M}$ et al showed a complicated 
Table 1. Comparison of basic findings (All appendicectomies - uncomplicated \& complicated appendicitis)

\begin{tabular}{|l|c|c|c|}
\hline & Junior Trainee (J) & Senior Trainee (ST) & p value \\
\hline No of surgeries & 103 & 49 & \\
\hline Mean Age (Range) & $24 y(8-62)$ & $27 y(8-75)$ & $\mathrm{p}=0.23$ \\
\hline Gender Male & 64 & 39 & $\mathrm{p}=0.125$ \\
Female & 24 & 25 & $\mathrm{p}=0.548$ \\
\hline Mean WBC $\left(\times 10^{3} / \mathrm{mm}^{3}\right)$ (Range) & $14(4-25)$ & $15(7-27)$ & $\mathrm{p}=0.347$ \\
\hline Mean CRP (mg/dl) (Range) & $48(5-276)$ & $61(4-376)$ & $\mathrm{p}=0.249$ \\
\hline Mean time duration from onset of & $2.01(1-7)$ & $2.43(1-8)$ & \\
\hline symptoms to operation (days)(Range) & & & \\
\hline
\end{tabular}

WBC- White Blood Cells, CRP- C Reactive Protein

Table 2. Operative details (All appendicectomies - uncomplicated \& complicated appendicitis)

\begin{tabular}{|l|c|c|c|}
\hline & Junior Trainee (JT) & Senior Trainee (ST) & P value \\
\hline Mean Operative time (min) & $71(25-180)$ & $68(30-150)$ & $\mathrm{p}=0.589$ \\
\hline Conversion to open & & $8(16.3 \%)$ & $\mathrm{p}=0.536$ \\
\hline Incidence of appendicular & $22(21.4 \%)$ & $17(34.7 \%)$ & $\mathrm{p}=0.079$ \\
Abscess and perforation & & & \\
(complicated appendicitis) & $3(1-7)$ & $3(1-8)$ & $\mathrm{p}=0.138$ \\
\hline Mean Hospital stay (days) & & 3 & $\mathrm{p}=0.342$ \\
(Range) & 2 & 2 & \\
\hline Complications & 0 & 1 & \\
Surgical site infection & 1 & 0 & \\
Paralytic ileus & & & \\
Residual abscess & & & \\
\hline
\end{tabular}

Table 3. Comparison of basic findings (After exclusion of appendicectomies for complicated appendicitis )

\begin{tabular}{|c|c|c|c|}
\hline & Junior Trainee (J) & Senior Trainee (ST) & p value \\
\hline No of surgeries & 81 & 32 & \\
\hline Mean Age (Range) & $26 \mathrm{v}(9-62)$ & $30 \mathrm{v}(11-75)$ & $p=0.147$ \\
\hline Gender & 48 & 17 & $p=0.552$ \\
\hline Female & 33 & 15 & \\
\hline Mean WBC (x10 $\left.10^{3} / \mathrm{mm}^{3}\right)$ (Range) & $14(5-24)$ & $15(7-24)$ & $p=0.324$ \\
\hline Mean CRP (mg/dlirRange) & $46(5-252)$ & $41(4-210)$ & $p=0.680$ \\
\hline
\end{tabular}

WBC- White Blood Cells, CRP-C Reactive Protein

Table 4. Operative details (After exclusion of appendicectomies for complicated appendicitis )

\begin{tabular}{|l|c|c|c|}
\hline & Junior Trainee (J) & Senior Trainee (ST) & P value \\
\hline $\begin{array}{l}\text { Mean Operative time (min) } \\
\text { (Range) }\end{array}$ & $67(25-165)$ & $60(30-150)$ & $\mathrm{p}=0.255$ \\
\hline Conversion to open & $3(3.7 \%)$ & $0(0.0 \%)$ & $\mathrm{p}=0.270$ \\
\hline Mean Hospital stay (days) & $3(1-7)$ & $2(1-5)$ & $\mathrm{p}=0.255$ \\
(Range) & 1 & 0 & $\mathrm{p}=0.528$ \\
\hline Complications & 1 & 0 & \\
Surgical site infection & 0 & 0 & \\
Paralytic ileus & 0 & 0 & \\
Residual abscess & & 0 & \\
\hline
\end{tabular}


appendicitis rate of $17 \%$ in a study comprising 1642 cases [7]. In our study, the ST group's complicated appendicitis rate was higher than that for the JT. This is because significantly complicated cases when anticipated pre-operatively were done by the seniors while the JT was given relatively fewer complex cases.

The conversion rate to open was $12.6 \%$ versus $16.3 \%$ in junior versus senior trainees' groups. A study conducted among the surgical trainees comprising 115 patients showed a conversion rate of $9.2 \%$ [8]. Many studies have shown conversion rates of LA to be $9 \%-12 \%$ [9]. Our study presented a slightly higher conversion rate. This might be due to the low threshold to open in complex cases. Even though ST had done more complicated cases of appendicectomy, the difference in the conversion rate was not statistically significant between the two groups in our study. There was another study which had compared a surgical resident and an experienced surgeon in performing LA, where the conversion rates were $7 \%$ and $22 \%$ respectively with a p-value of $0.04[10]$. The difference had stemmed from the fact that the experienced surgeon had performed more complex surgeries.

The mean operative time was 71 minutes and 68 minutes in junior and senior trainees' groups respectively. Lapo Bencini et al reported a mean operative time of 67 minutes and 60 minutes by the surgical resident and the experienced surgeon respectively [10]. This was comparable with our study. Another study indicated a mean operative time of 52 minutes which was less than our study [6]. Their trainees had to perform a minimum of 25 open cases appendicectomy before embarking on LA. On the contrary, our junior trainees did not have comparable experience with open appendicectomy before performing laparoscopic surgery. A couple of studies showed a mean operative time higher than that of our study (96 minutes and 102 minutes) $[11,12]$.

Our overall complication rate was 3.9\% which was less than the published data. Carrasco-Prats $\mathrm{M}$ et al showed a $13 \%$ complication rate in their study comprising 224 cases and Martin LC et al published a complication rate of $13.1 \%$ (81) $[9,11]$. In our study, the length of hospital stay was three days in both groups. This is like the studies of Carrasco-Prats $\mathrm{M}$ et al. and Mutter et al where the hospital stay was an average of 4.9 days $[9,13]$.

In this retrospective study, we were unable to find consistent data about BMI of patients, position of the appendix, and preoperative abdominal examination findings. As these factors also influence the surgery, comparing the JT and ST groups based on these parameters would have provided more significance to this study. Hence, we consider it as a limitation of our study.
In conclusion, our findings are comparable to previously published data in terms of complicated appendicitis, conversion rates, operative time, hospital stay, and postoperative complications. Therefore, we propose that LA could safely be performed by the junior surgical trainees, who have limited experience in minimal access surgery with acceptable outcomes.

All authors disclose no conflict of interest. The study was conducted in accordance with the ethical standards of the relevant institutional or national ethics committee and the Helsinki Declaration of 1975, as revised in 2000 .

\section{References}

1. Markar SR, Pinto D, Penna M, et al. A comparative international study on the management of acute appendicitis between a developed country and a middle income country. Int J Surg. 2014; 12(4):357 360. doi:10.1016/j.ijsu.2014.01.008

2. Alnaser MK, Hassan QA, Hindosh LN. Effectiveness of conservative management of uncomplicated acute appendicitis: A single hospital based prospective study. International Journal of Surgery Open. 2018; 10:1-4.

http://dx.doi.org/10.1016/j.ijso.2017.11.007

3. The Intercollegiate Surgical Curriculum programme [Internet]. The Intercollegiate Surgical Curriculum General Surgery-2016. Available on https://www.iscp.ac.uk/static/public/syllabus/sylla bus_gs_2016.pdf

4. Nestel D, Burgess A. Surgical education and the theoretical concept of communities of practice. Journal of Health Specialties. 2014; 2(2):49. http://dx.doi.org/10.4103/1658-600x.131746

5. Wenger E. Communities of Practice: Learning, Meaning, and Identity. Cambridge University Press, 1998.

6. Morris C. Replacing 'the firm': re-imagining clinical placements as time spent in Communities of Practice. In: Cook V, Daly C, Newman, M. editors. Work Based Learning in Clinical Settings — Insights from Socio-Cultural Perspectives. Oxford: Radcliffe Medical, 2012.

7. Yilmaz M. Unusual histopathological findings in appendectomy specimens from patients with suspected acute appendicitis. World Journal of Gastroenterology. 2013; 19(25):4015. http://dx.doi.org/10.3748/wjg.v19.i25.4015

8. Tata MD, Singh R, Bakar AA, Selvindoss P, Kandasami P, Gurunathan R. Laparoscopic Appendicectomy: The Ideal Procedure for Laparoscopic Skill Training for Surgical Registrars. Asian Journal of Surgery. 2008 Apr; 31(2):55-8. http://dx.doi.org/10.1016/s1015-9584(08)60058-5

9. Carrasco-Prats M, Soria Aledo V, Luján-Mompeán JA, RíosZambudio A, Pérez-Flores D, Parrilla-Paricio P. Role of appendectomy in training for laparoscopic surgery. Surgical Endoscopy. 2003 Jan 1; 17(1):111-4. http://dx.doi.org/10.1007/s00464-001-9199-y

10. Lapo Bencini, Marco Bernini, Francesco Martini, Michele Rossi, Cinzia Tommasi, et al. Laparoscopic Appendectomy Performed by Residents and Experienced Surgeons. Journal of the society of Laparoscopy and Robotic surgeons. 2009 Jul-Sep; 13(3): 391-397. 
11.Martin LC, Puente I, Sosa JL, Bassin A, Breslaw R, McKenney MG, et al. Open Versus Laparoscopic Appendectomy A Prospective Randomized Comparison (Abstract). Annals of Surgery. 1995 Sep; 222(3):256-62.

http://dx.doi.org/10.1097/00000658-199509000-00004

12.Scott-Conner Ceh, Hall Tj, Anglin Bl, Muakkassa Ff. Laparoscopic Appendectomy Initial Experience in a Teaching Program (Abstract). Annals of Surgery. 1992 Jun; 215(6):660-8. http://dx.doi.org/10.1097/00000658-199206000-00013
13.Mutter D, Vix M, Bui A, Evrard S, Tassetti V, Breton JF, et al. Laparoscopy not recommended for routine appendectomy in men: Results of a prospective randomized study. Surgery. 1996 Jul; 120(1):71-4. http://dx.doi.org/10.1016/s00396060(96)80243-1 